\title{
Commentary on Workplace Lactation-Support
}

\section{Tyler Lennon and Earnestine Willis, MD, MPH}

Medical College of Wisconsin, Milwaukee, Wisconsin, USA

\section{Workplace Lactation-Support and its Effects}

Breastfeeding and the use of human milk provide infants with unique benefits that are both nutritional and non-nutritional [1]. The literature supports that infants who are breastfed have a reduced risk of otitis media, gastrointestinal infections, lower respiratory infections, asthma, childhood leukaemia, diabetes and obesity [1]. In addition, breastfeeding is associated with an increase in both verbal and performance IQ [2]. Uniquely, breastfeeding has also demonstrated to be beneficial for lactating mothers, most notably a reduction in risk of breast and ovarian cancer [3]. However, Figure 1 indicates how the United States has some of shortest, 3 and 6 month, exclusive breastfeeding duration rates among developed countries [4]. Other countries such as Hungary, Iceland, and Norway have the highest 3 month exclusive breastfeeding duration rates, and Sweden and Hungary have the highest 4 month exclusive breastfeeding duration rates. However, breastfeeding duration rates in the United States have been increasing since this report in 2005. Most recently in 2011, the 6 month exclusive breastfeeding duration rate in the United States was $18.8 \%$ [5] which was an increase from $11.9 \%$ in 2005 shown in Figure 1. Despite this increase, the United States still has some of the shortest exclusive breastfeeding duration rates among developed countries and therefore not surprisingly, the worst lactation-support of any of the developed countries. According to the State of the World's Mothers Report for 2012, the United States ranks last on the Breastfeeding Policy Scorecard for developed countries [6]. This report rated countries based on their breastfeeding policies in categories such as weeks given for paid maternity leave, the right to daily nursing breaks at work, and percent of hospitals that are baby-friendly. In order to receive a "very good" overall rating, countries had to receive a rating of "good" or better across all indicators. The poor breastfeeding policy score for the United States is mostly due to the fact that the United States is the only economically advanced country in the world where employers are not required to provide paid maternity leave. This leads to women returning to work earlier than other countries, and early return to work is associated with the discontinuation of breastfeeding $[7,8]$. In addition, employers are not required to pay employees

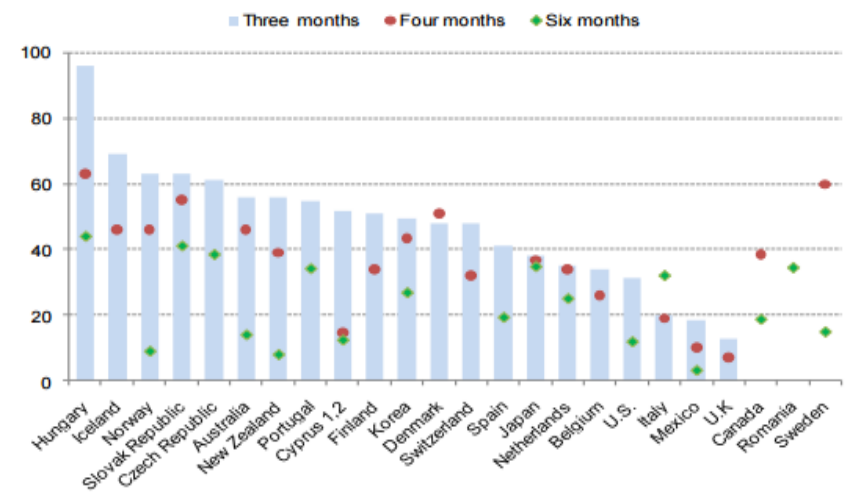

Figure 1: Proportion of children who were exclusively breastfed at 3, 4 and 6 months, around 2005 [4] for breaks needed to nurse and only $2 \%$ of hospitals are certified as "baby-friendly". Furthermore, the Organization for Economic Cooperation and Development (OECD) found that the incidence of exclusive breastfeeding and its duration tends to be longer in countries with longer periods of maternity/parental leave, such as the Nordic countries and the Czech Republic [4]. However, it should be noted that the relationship does not always hold as British and Irish experiences illustrate. The high incidence of breastfeeding in countries such as Norway and Sweden are most likely due to their policies of maternity leave/rights [6]. However, a few countries such as Hungary have high breastfeeding rates despite a fair rating on the Breastfeeding Policy Scorecard. Cultural attitudes towards breastfeeding play a vital role [9], and therefore the cultural norm toward breastfeeding in these countries may be driving the higher breastfeeding rates despite their poor breastfeeding policy. Moreover, the United States has one of the worst infant mortality rates amongst OECD countries [10], whereas countries with more breastfeeding support such as Norway, Iceland, and Sweden rank at the top of the list for lowest infant mortality rate. Therefore, policy makers and employers in countries with shorter maternity leave, such as the United States, need to recognize that mothers are returning to work sooner than other countries and consider providing adequate workplace lactation-support.

\section{Increasing Need for Workplace Lactation-Support}

The need for increased workplace lactation-support is even greater for low-income, African American, and less-educated women who have disproportionally lower breastfeeding duration rates. In fact, according to the CDC data in 2011, women who breastfed their infant at six months of age and received Special Supplemental Nutrition Program for Women, Infants and Children (WIC) reported a rate of $37.8 \%$, the non-Hispanic Black rate was $35.0 \%$ and those having a less than high school education breastfeeding rate was $34.4 \%$ [5] . These breastfeeding rates are much lower than both the United States national average of $49.4 \%$ and the Healthy People 2020 Goal of $60.6 \%$ [11]. Therefore, due to the unquestionable benefits of breastfeeding for infants and mothers, interventions should focus on increasing breastfeeding opportunities among vulnerable populations in the workplace.

There are many well-documented barriers to breastfeeding in this susceptible population such as lack of knowledge [12], social norms [13], poor family and social support [14], lactation problems [15], and employment $[16,17]$. Recognizing the increasing number of women in the workforce, full-time employment is an ever increasing barrier to breastfeeding among low-income women. According to the United

*Corresponding author: Willis E, Medical College of Wisconsin, Milwaukee, Wisconsin, USA, Tel: 414-955-4131; E-mail: ewillis@mcw.edu

Received June 16, 2015; Accepted August 19, 2015; Published August 21, 2015

Citation: Lennon T, Willis E (2015) Commentary on Workplace Lactation-Support Review Pub Administration Manag 3: 162. doi:10.4172/2315-7844.1000162

Copyright: $\odot 2015$ Lennon T, et al. This is an open-access article distributed under the terms of the Creative Commons Attribution License, which permits unrestricted use, distribution, and reproduction in any medium, provided the original author and source are credited. 


\section{Breastfeeding Policy Scorecard for Developed Countries}

\begin{tabular}{|c|c|c|c|c|c|c|c|c|c|c|c|}
\hline \multirow{3}{*}{$\begin{array}{l}\text { Norway } \\
\end{array}$} & \multicolumn{2}{|c|}{$\begin{array}{l}\text { BREASTFEEDING } \\
\text { POLICY SUMMARY }\end{array}$} & \multicolumn{2}{|c|}{$\begin{array}{l}\text { PAID MATERNITY } \\
\text { LEAVE' }\end{array}$} & \multicolumn{2}{|c|}{$\begin{array}{l}\text { RIGHT TO DAILY } \\
\text { NURSING BREAKS }\end{array}$} & \multirow{2}{*}{$\begin{array}{l}\text { \% HOSPITALS } \\
\text { THAT ARE } \\
\text { BABY } \\
\text { FRIENDLY }\end{array}$} & \multirow{2}{*}{$\begin{array}{l}\text { STATE OF } \\
\text { POLICY } \\
\text { SUPPORT } \\
\text { FOR THE } \\
\text { CODE }^{4}\end{array}$} & \multicolumn{3}{|c|}{$\begin{array}{l}\text { BREASTFEEDING } \\
\text { PRACTICES }\end{array}$} \\
\hline & Score & Rating & $\begin{array}{l}\text { Length } \\
\text { (weeks) }\end{array}$ & $\begin{array}{c}\% \\
\text { Wages paid }\end{array}$ & Y/N & $\begin{array}{l}\text { Length of } \\
\text { coverage } \\
\text { (months) }\end{array}$ & & & $\begin{array}{c}\text { Ever } \\
\text { breastfed } \\
\%\end{array}$ & $\begin{array}{c}\text { Exclusive at } \\
3 \text { months } \\
\%\end{array}$ & $\begin{array}{c}\text { Any at } \\
6 \text { months } \\
\%\end{array}$ \\
\hline & 9.8 & Very good & 36 or $46^{2}$ & $100,80 \%$ & $Y^{*}$ & no limit & $79 \%$ & Good & 99 & 70 & 80 \\
\hline Slovenia & 9.6 & Very good & 15 & $100 \%$ & $Y$ & no limit & $79 \%$ & Good & 97 & - & - \\
\hline Sweden & 9.6 & Very good & $60^{2}$ & $80 \%^{\dagger}$ & $Y^{*}$ & no limit & $100 \%$ & Good & 98 & $60(4 \mathrm{~m})$ & 72 \\
\hline Luxembourg & 9.4 & Very good & 16 & $100 \%$ & $Y$ & no limit & $>50 \%^{\mathrm{B}}$ & Good & 90 & $26(4 \mathrm{~m})$ & 41 \\
\hline Austria & 9.0 & Good & 16 & $100 \%$ & Y & no limit & $>15 \%^{\mathrm{B}}$ & Good & 93 & 60 & 55 \\
\hline Lithuania & 9.0 & Good & 18 & $100 \%$ & Y & no limit & $>15 \%^{8}$ & Good & 98 & 41 & 31 \\
\hline Latvia & 8.8 & Good & 16 & $100 \%$ & Y & 18 & $47 \%$ & Good & 92 & 63 & 46 \\
\hline Czech Republic & 8.6 & Good & 28 & $60 \%$ & Y & $\geq 12$ & $55 \%$ & Good & 96 & - & 53 \\
\hline Netherlands & 8.6 & Good & 16 & $100 \%$ & Y & 9 & $63 \%$ & Good & 81 & 30 & 37 \\
\hline Germany & 8.4 & Good & 14 & $100 \%$ & Y & no limit & $4 \%$ & Good & 96 & $33(4 \mathrm{~m})$ & 48 \\
\hline Estonia & 8.2 & Good & 20 & $100 \%$ & Y & 18 & $0 \%^{8}$ & Good & 82 & - & 40 \\
\hline Poland & 8.2 & Good & 20 & $100 \%$ & Y & no limit & $15 \%$ & Good & 71 & 31 & - \\
\hline Portugal & 8.2 & Good & 17 or $21^{2}$ & $100,80 \%$ & $Y$ & no limit & $2 \%$ & Good & 90 & 52 & 29 \\
\hline France & 8.0 & Good & 16 & $100 \%{ }^{\dagger}$ & $Y^{*}$ & 12 & $1 \%$ & Good & 65 & - & - \\
\hline Belgium & 7.8 & Good & 15 & $82,75 \% \dagger$ & $Y$ & 7 & $6 \%$ & Good & 72 & 25 & 25 \\
\hline Ireland & 7.8 & Good & $26(16)$ & $80 \%^{\dagger}$ & Y & 6.5 & $35 \%$ & Good & 46 & - & - \\
\hline Italy & 7.8 & Good & 20 & $80 \%$ & $Y$ & 12 & $2 \%$ & Good & 91 & 47 & 47 \\
\hline Switzerland & 7.8 & Good & 14 & $80 \%{ }^{\dagger}$ & $Y^{*}$ & 12 & $>50 \%^{8}$ & Fair & 92 & - & 41 \\
\hline New Zealand & 7.6 & Good & $14^{2}$ & $100 \%$ & $Y^{*}$ & - & $>75 \%^{\circ}$ & Fair & 88 & 56 & - \\
\hline Cyprus & 7.5 & Good & 18 & $75 \%$ & Y & 6 & - & Good & 79 & 52 & - \\
\hline Denmark & 7.4 & Good & 18 & $100 \%^{\dagger}$ & no rig & breaks $\mathrm{s}^{\prime}$ & $39 \%$ & Good & 98 & 48 & - \\
\hline Greece & 7.4 & Good & 17 & $100 \%$ & Y & 12 & $0 \%$ & Good & 86 & - & - \\
\hline Slovak Republic & 7.4 & Good & 28 & $55 \%$ & Y & 12 & $29 \%$ & Good & 92 & $57(4 \mathrm{~m})$ & - \\
\hline Spain & 7.4 & Good & 16 & $100 \%$ & $\mathrm{Y}$ & 9 & $3 \%$ & Good & 76 & 44 & 40 \\
\hline United Kingdom & 7.2 & Good & $39(13)$ & $90 \%$ & no rig & breaks $\ddagger$ & $17 \%$ & Good & 81 & 13 & 25 \\
\hline Finland & 6.8 & Fair & 18 & $70+\%$ & no rig & breaks ${ }^{\ddagger}$ & $12 \%$ & Good & 93 & 51 & 60 \\
\hline Israel & 6.8 & Fair & 12 & $100 \%$ & Y & 7.5 & $0 \%^{8}$ & Good & - & - & - \\
\hline Japan & 6.8 & Fair & 14 & $67 \%$ & $Y^{*}$ & 12 & $6 \%^{8}$ & Fair & 97 & 38 & - \\
\hline Hungary & 6.6 & Fair & 24 & $70 \%$ & $Y$ & 9 & $7 \%^{8}$ & Good & 96 & $62(4 \mathrm{~m})$ & - \\
\hline Liechtenstein & 6.2 & Fair & 20 & $80 \%$ & Y & no limit & $0 \%^{8}$ & Poor & - & - & - \\
\hline Canada & 5.4 & Fair & 17 & $55 \%^{\dagger}$ & no rig & breaks $^{\ddagger}$ & $4 \%^{8}$ & Fair & 90 & 52 & 54 \\
\hline Iceland & 5.4 & Fair & $13^{2}$ & $80 \%$ & no rig & breaks ${ }^{\ddagger}$ & $0 \%$ & Poor & 98 & $48(4 \mathrm{~m})$ & 65 \\
\hline Monaco & 5.4 & Fair & 16 & $90 \%$ & $\mathrm{Y}$ & 12 & $0 \%^{8}$ & Poor & - & - & - \\
\hline Australia & 4.8 & Poor & $18^{2}$ & flat rate & no rig & breaks ${ }^{\ddagger}$ & $>15 \%^{8}$ & Fair & 96 & 39 & 60 \\
\hline Malta & 4.4 & Poor & 14 & $100 \%$ & no rig & breaks ${ }^{\ddagger}$ & $0 \%^{8}$ & Poor & 62 & - & - \\
\hline United States & 4.2 & Poor & (12) & unpaid & $Y^{*}$ & 12 & $2 \%^{8}$ & Poor & 75 & 35 & 44 \\
\hline
\end{tabular}

Figure 2: Breastfeeding Policy Scorecard for Developed Countries [6]. A red category indicates "very good", dark pink indicates "good", light pink indicates "fair", and white indicates "poor".

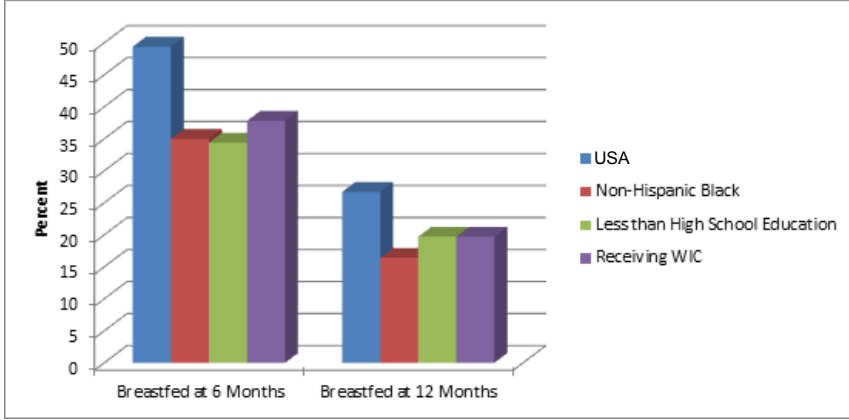

Figure 3: Breastfeeding rates among United States women who did any breastfeeding at 6 and 12 months in 2011 [5]

State Census Bureau, $62.1 \%$ of mothers with children under one year of age were in the workforce in 2012 [18]. Furthermore, approximately $70 \%$ of employed mothers with children younger than 3 years' work full time [19]. Therefore, society needs to appreciate the prevailing increase of women in the workforce; recognize that returning to work is significantly associated with discontinuation of breastfeeding $[7,8]$; and take actions to increase workplace lactation-support. Furthermore, lactation-support in the workplace disproportionately impacts lowincome women due to them having more barriers to combining work and lactation [20]. The past Surgeon General's Blueprint for Action on Breastfeeding (2001) stated that African American women return to work on average earlier than other racial/ethnic groups and tend to work in jobs that do not support lactation [19]. All of these factors lead to shorter durations of breastfeeding which may have negative health implications for infants. Given the substantial presence of women in the workforce, it is critical to provide workplace lactation-support.

\section{Policy Recommendations for Establishing Workplace Lactation-Support Programs}

Women in the workforce do not feel they have breastfeeding support for multiple reasons. These reasons include lack of adequate or flexible break time [21], lack of an accommodating space [22], unsupportive supervisors [23], and pressure from co-workers [24]. In other words, many businesses do not have a lactation policy, designated space or accommodations for women to use a breast pump. In 2009, a large survey found that only $25 \%$ of businesses had a lactation program or made special accommodations for breastfeeding [25]. Therefore, in 2010 as part of the Affordable Care Act, a provision called the Reasonable Break Time for Nursing Mothers was enacted that required 
businesses with over 50 employees to provide reasonable break time for employees to express breast milk for a child up to one year of age [26]. In addition, employers must also provide a private space, other than a bathroom or locker room for expressing breast milk. Despite this law, many businesses have not implemented a lactation-support program and/or need concrete strategies to implement one. A study by Brown et al. documented how some businesses do not feel that breastfeeding support should be a high priority. These employers also reported barriers to having a lactation-support program that included lack of appropriate private space, lack of time to give employees to express breast milk, as well as financial and liability issues [24]. In addition, although this law gives women the legal right to express breast milk at work, many women are reluctant to ask for their workplace lactation rights for fear that they might lose their job [17]. This is discouraging because there is no need for employer inhibition; workplace lactation programs have been shown to be both beneficial to the employees as well as the employers. For every $\$ 1$ spent to create and support a workplace lactation program there is a $\$ 3$ return on investment [27]. This is accomplished by mothers taking fewer sick days to care for their infants in addition to lower health care and insurance costs. Furthermore, businesses improve their family-friendly image in their community, retain a trained and talented workforce, and women report higher job satisfaction [28]. In addition, other factors within the business such as having quality interpersonal communication [23], encouragement from employers [29] and even the size of the employer [24] influence mothers' perceived support and thus, breastfeeding duration rates. Therefore, no two businesses are the same, each business needs to have a unique plan to support working mothers, and policies need to be tailored to each individual business. Ultimately, there is a need for interventions that facilitate employers designing strategies to overcome lactation-support barriers.

\section{Conclusion}

In conclusion, the workplace environment needs to be more engaged to offer lactation strategies and options to the rising percent of women in the workforce in order to increase breastfeeding duration. Specific interventions need to target lactation-support opportunities for vulnerable populations such as low-income, African American, and less-educated women. By increasing workplace lactation-support, businesses can benefit, women have greater opportunities to continue lactation for longer periods of time, and children will be healthier.

\section{References}

1. http://pediatrics.aappublications.org/content/early/2012/02/22/peds.2011 3552.full.pdf

2. Horwood LJ, Darlow BA, Mogridge N (2001) Breast milk feeding and cognitive ability at 7-8 years. Arch Dis Child Fetal Neonatal Ed 84: F23-F27.

3. Ip S, Chung M, Raman G, Chew P, Magula N, et al. (2007) Breastfeeding and maternal and infant health outcomes in developed countries. Evid Rep Technol Assess (Full Rep) 153: 1-186.

4. http://www.oecd.org/els/family/43136964.pdf

5. http://www.cdc.gov/breastfeeding/data/NIS_data/index.htm

6. http://www.savethechildren.org/atf/cf/\%7B9def2ebe-10ae-432c-9bd0df91d2eba74a\%7D/STATE-OF-THE-WORLDS-MOTHERS-REPORT-2012FINAL.PDF

7. Ryan AS, Wenjun Z, Acosta A (2002) Breastfeeding continues to increase into the new millennium. Pediatrics 110: 1103-1109.

8. Guendelman S, Kosa JL, Pearl M, Graham S, Goodman J, et al. (2009) Juggling Work and Breastfeeding: Effects of Maternity Leave and Occupational Characteristics. Pediatrics 123: e38-e46.
9. Tarrant RC, Kearney JM (2008) Session 1: Public health nutrition Breastfeeding practices in Ireland. Proc Nutr Soc 67: 371-380.

10. http://stats.oecd.org/index.aspx?DataSetCode=HEALTH_STAT

11. http://www.healthypeople.gov/2020/topics-objectives/topic/maternal-infantand-child-health/objectives

12. McFadden A, Toole G (2006) Exploring women's views of breastfeeding: a focus group study within an area with high levels of socio-economic deprivation. Matern Child Nutr 2: 156-168.

13. Stewart-Knox B, Gardiner K, Wright M (2003) What is the problem with breastfeeding? A qualitative analysis of infant feeding perceptions. J Hum Nutr Diet 16: 265-273.

14. Dennis CL (2002) Breastfeeding initiation and duration: a 1990-2000 literature review. J Obstet Gynecol Neonatal Nurs 31: 12-32.

15. Li R, Fein SB, Chen J, Grummer-Strawn LM (2008) Why mothers stop breastfeeding: mothers' self-reported reasons for stopping during the first year. Pediatrics 122:S69-S76.

16. Johnston ML, Esposito N (2007) Barriers and facilitators for breastfeeding among working women in the United States. J Obstet Gynecol Neonatal Nurs 36: 9-20.

17. Johnson AM, Kirk R, Muzik M (2015) Overcoming workplace barriers: A focus group study exploring African American mothers' needs for workplace breastfeeding support. J Hum Lact 31: 425-433.

18. http://www.census.gov/content/dam/Census/library/publications/2014/demo/ p20-575.pdf

19. Satcher DS (2001) DHHS Blueprint for Action on Breastfeeding. Public Health Rep 116: 72-73.

20. Kimbro RT (2006) On-the-Job Moms: Work and breastfeeding initiation and duration for a sample of low-income women. Matern Child Health J 10: 19-26.

21. Li R, Hsia J, Fridinger F, Hussain A, Benton-Davis S, et al. (2004) Public beliefs about breastfeeding policies in various settings. Journal of the American Dietetic Association 104: 1162-1168.

22. Rojjanasrirat W (2004) Working women's breastfeeding experiences. MCN Am J Matern Child Nurs 29: 222-227.

23. Anderson J, Kuehl RA, Drury SA, Tschetter L, Schwaegerl M, et al. (2015) Policies aren't enough: The importance of interpersonal communication about workplace breastfeeding support. J Hum Lact 31: 260-266.

24. Brown CA, Poag S, Kasprzycki C (2001) Exploring large employers' and smal employers' knowledge, attitudes, and practices on breastfeeding support in the workplace. J Hum Lact 17: 39-46.

25. http://www.shrm.org/Research/SurveyFindings/Articles/Documents/09-0295 Employee_Benefits_Survey_Report_spread_fnl.pdf

26. www.dol.gov/whd/nursingmothers/Sec7rFLSA_btnm.htm

27. http://www.womenshealth.gov/breastfeeding/employer-solutions/index.html

28. Wait WM, Christakis D (2015) Relationship of maternal perceptions of workplace breastfeeding support and job satisfaction. Breastfeed Med 10: 222-227.

29. Tsai SY (2013) Impact of a breastfeeding-friendly workplace on an employed mother's intention to continue breastfeeding after returning to work. Breastfeed Med 8: 210-216. 